\title{
Manipulating the NF- $\kappa B$ pathway in macrophages using mannosylated, siRNA-delivering nanoparticles can induce immunostimulatory and tumor cytotoxic functions
}

Ryan A Ortega ${ }^{1-3}$

Whitney Barham ${ }^{3}$

Kavya Sharman ${ }^{4}$

Oleg Tikhomirov ${ }^{3}$

Todd D Giorgio ${ }^{1-3}$

Fiona E Yull ${ }^{3}$

'Department of Biomedical

Engineering, Vanderbilt University,

${ }^{2}$ Vanderbilt Institute for Nanoscale

Science and Engineering, ${ }^{3}$ Department

of Cancer Biology, Vanderbilt-Ingram

Cancer Center, ${ }^{4}$ Department of

Neuroscience, Vanderbilt University, Nashville, TN, USA
Correspondence: Todd D Giorgio; Fiona E Yull

Department of Cancer Biology,

Vanderbilt-Ingram Cancer Center, 2220

Pierce Ave, Nashville, TN 37232, USA

Email todd.d.giorgio@vanderbilt.edu;

fiona.yull@vanderbilt
This article was published in the following Dove Press journal:

International Journal of Nanomedicine

18 May 2016

Number of times this article has been viewed

\begin{abstract}
Tumor-associated macrophages (TAMs) are critically important in the context of solid tumor progression. Counterintuitively, these host immune cells can often support tumor cells along the path from primary tumor to metastatic colonization and growth. Thus, the ability to transform protumor TAMs into antitumor, immune-reactive macrophages would have significant therapeutic potential. However, in order to achieve these effects, two major hurdles would need to be overcome: development of a methodology to specifically target macrophages and increased knowledge of the optimal targets for cell-signaling modulation. This study addresses both of these obstacles and furthers the development of a therapeutic agent based on this strategy. Using ex vivo macrophages in culture, the efficacy of mannosylated nanoparticles to deliver small interfering RNA specifically to TAMs and modify signaling pathways is characterized. Then, selective small interfering RNA delivery is tested for the ability to inhibit gene targets within the canonical or alternative nuclear factor-kappaB pathways and result in antitumor phenotypes. Results confirm that the mannosylated nanoparticle approach can be used to modulate signaling within macrophages. We also identify appropriate gene targets in critical regulatory pathways. These findings represent an important advance toward the development of a novel cancer therapy that would minimize side effects because of the targeted nature of the intervention and that has rapid translational potential.
\end{abstract}

Keywords: nanotechnology, targeted nanoparticles, cancer immunology, RNAi

\section{Introduction}

Many therapeutic strategies for cancer immunotherapy, such as adoptive T-cell transfer for prostate cancer, focus on activating or enhancing adaptive immunity against cancer cells. ${ }^{1,2}$ However, cells of the innate immune system are also an attractive target for cancer therapies. Tumor-associated macrophages (TAMs) have been implicated as one of the most prevalent and impactful types of immune cells in tumor-related stroma. ${ }^{4-6}$ In most cases, interactions between the tumor cells and the resident or infiltrating macrophage population cause the macrophages to adopt a phenotype characterized by the constant, low-level production of inflammatory cytokines. ${ }^{7}$ This produces a state of smoldering inflammation in the tumor and surrounding tissue. This type of inflammation is insufficient to induce apoptosis or other mechanisms of tumor cell death but is significant enough to cause survivable DNA damage in the genetic material of tumor cells as well as activate survival signals in the nearby cells. ${ }^{8,9}$ TAMs also contribute to the immunosuppressive microenvironment by producing cytokines, such as interleukin 
(IL)-10, which inhibit the ability of resident immune cells to act against tumor cells and prevent the recruitment of CD $8^{+}$ T-cells, natural killer cells (NK cells), and other cytotoxic or proinflammatory immune cells. ${ }^{10-12}$ Furthermore, TAMs produce trophic cytokines, can degrade the surrounding connective tissue, and induce angiogenesis, allowing the primary tumor to grow. ${ }^{13-15}$ Finally, TAMs participate in the metastatic process by creating pathways that aid in tumor cell intravasation. ${ }^{16,17}$

It has been reported that the tumorigenic and metastatic effects generated by TAMs can be reduced or removed by ablating macrophages with liposomal clodronate in mouse models of human cancer. ${ }^{17-19}$ Though TAMs have adopted a protumor phenotype, we and others have shown that they retain the potential to produce cytotoxic levels of inflammation, lyse surrounding cells, and coordinate an immune response from cells of the innate and adaptive immune system. ${ }^{21-24}$ The ability to recapitulate these cytotoxic and immunostimulatory functions in TAMs, thus creating an antitumor phenotype, would be a powerful therapeutic tool for treating tumors and metastases with a significant macrophage population. An antitumor macrophage phenotype could potentially be produced by strategically manipulating the nuclear factor-kappaB (NF- $\mathrm{KB})$ signaling pathway in TAMs. The two arms of the NF- $\kappa B$ pathway (classical and alternative) are potent controllers of the macrophage phenotype and regulate many of their inflammatory and trophic functions (Figure 1)..$^{25-28}$

Previous work supports the idea of therapeutically targeting TAMs with the intention of reeducating them to become tumor killing rather than tumor supportive. In addition, $\mathrm{NF}-\mathrm{kB}$ signaling may be a phenotypic fulcrum that could promote this switch if manipulated appropriately. However, little progress has been made toward translating this knowledge into viable, clinically relevant therapeutic agents. This study addresses two of the major hurdles that must be overcome to move this type of therapy forward: 1) developing a means to achieve macrophage-specific and pathway-specific cellsignaling modulation and 2) gaining additional knowledge about which components of the NF- $\mathrm{KB}$ pathway would be the most advantageous to target.

A possible mechanism to change NF- $\kappa B$ signaling in TAMs is the use of small interfering RNAs (siRNAs). These are short (20-25 bp), double-stranded RNA sequences that can activate RNA interference in cells, resulting in the degradation of intracellular messenger RNA (mRNA) sequences that are bound by the guide strand of the siRNA. ${ }^{29}$ This effect targets a specific mRNA sequence, and the strength

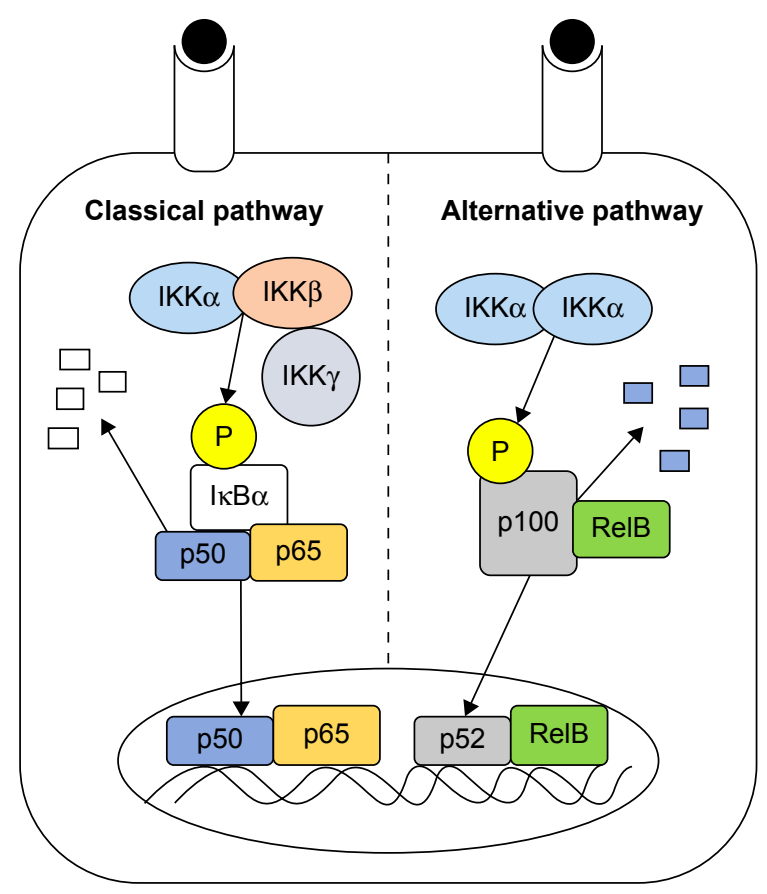

Figure I Overview of the two arms of the NF- $\kappa B$ pathway.

Notes: The classical pathway is broadly activated by immunostimulatory molecules: TNF- $\alpha$, LPS, IL-I, IFN $\gamma$, and others. Activation of the classical pathway causes the IKK complex (IKK $\alpha$, IKK $\beta$, and IKK $\gamma$ ) to phosphorylate the inhibitor of the classical pathway $(\mid \kappa B \alpha)$, resulting in its degradation by proteasomes. The transcriptionally active classical NF- $\kappa B$ heterodimer ( $p 50: p 65)$ is then free to enter the nucleus and affect DNA transcription. ${ }^{3}$ The alternative NF- $\kappa B$ pathway is activated by a narrower set of ligands, most of which are tumor necrosis factor family proteins: TNF- $\alpha$, CD40 ligand, RANK ligand, and more. Activation of the alternative pathway causes an IKK $\alpha: I K K \alpha$ homodimer to phosphorylate pI00, which is bound to RelB. A portion of pl00 acts as the inhibitor of the alternative pathway; its structure and function are analogous to $I \kappa B \alpha$ in the classical pathway. After phosphorylation, a portion of pl00 is degraded in proteasomes, resulting in pl00 digestion to the transcriptionally active form, $\mathrm{p} 52$. $\mathrm{p} 52$ :RelB heterodimers are then free to enter the nucleus and affect DNA transcription. ${ }^{20}$

Abbreviations: NF- $\kappa B$, nuclear factor-kappaB; TNF- $\alpha$, tumor necrosis factor- $\alpha$; LPS, lipopolysaccharide; IL-I, interleukin-I; INF $\gamma$, interferon $\gamma$; RANK, receptor activator of nuclear factor kappaB.

and duration of the effect can be tuned by altering siRNA dosing. To facilitate delivery of NF- $\kappa B$ siRNA to TAMs, we have developed a targeted polymeric nanoparticle capable of encapsulating and protecting siRNA sequences. The particle is designed such that the $\mathrm{pH}$-responsive core disrupts the endosomal compartment upon cellular uptake, rupturing the organelle as the internal $\mathrm{pH}$ drops and releasing the functional siRNA into the cytoplasm. ${ }^{30-32}$ The particle has a modular surface that can be modified with targeting ligands using facile, copper-catalyzed "click" chemistry. ${ }^{33}$ We have functionalized the surface of these particles with mannose as a targeting ligand in order to facilitate uptake of the particles in TAMs, which have increased amounts of mannose receptor (CD206) on their surface. ${ }^{34,35}$ The mannose receptor is an endosomal pattern-recognition receptor, which, when present at high levels, is associated with suppression of the classical 
immune response. ${ }^{36} \mathrm{We}$ have shown previously that uptake of these mannosylated endosomal escape nanoparticles (MnNPs) by macrophages is mannose dependent and that uptake of the MnNPs is enhanced in macrophages compared to uptake of untargeted, hydroxyl-capped nanoparticles (OHNPs). ${ }^{37}$ MnNPs are designed to condense and shield siRNA in the interior of the particle for optimal systemic transport, enter the tumor vasculature via the enhanced permeability and retention effect, specifically target TAMs in the tumor microenvironment, and escape the low $\mathrm{pH}$ of the late endosome to deliver functional siRNA into the cytoplasm. We recently determined that MnNPs are biocompatible in vivo and that the targeting moiety enhances uptake in TAMs in vivo. ${ }^{38}$ The present study takes this work forward by validating the efficacy of MnNPs as transfection agents for delivering functional siRNA to macrophages and measuring siRNA-mediated modulation of NF- $\kappa \mathrm{B}$ activity resulting from suppression of signal transduction proteins.

In order to address the second hurdle and determine the optimal strategy for modulation of NF- $\kappa \mathrm{B}$ signaling, we have screened several siRNA sequences specific for NF- $\kappa B$ pathway proteins using both the commercial transfection agent Lipofectamine and our MnNPs. The prevailing dogma has been that suppression of NF- $\kappa \mathrm{B}$ signaling reduces protumor TAM effects. ${ }^{39}$ However, our recent work in mice with activatable classical NF- $\mathrm{KB}$ signaling in macrophages has shown that strategic activation of the classical pathway reduces metastatic tumor burden in a tail vein-injected mouse model of metastatic breast cancer and in a model of metastatic melanoma. ${ }^{23,40}$ In line with these studies, we discovered that MnNP-delivered siRNA against the inhibitor protein of the classical pathway was capable of activating the $\mathrm{NF}-\kappa \mathrm{B}$ pathway and inducing a proinflammatory, immunogenic phenotype in the transfected macrophages. This result highlights a novel strategy to generate antitumor functions in TAMs and indicates that the combination of our novel MnNP with I $\mathrm{B} \alpha$ siRNA could represent the first step toward harnessing TAM-targeted siRNA strategies for cancer therapy.

\section{Materials and methods Cell culture}

Unless otherwise stated, all primary cells and cell lines used in this study were maintained in Dulbecco's Modified Eagle's Medium (Corning Incorporated, Corning, NY, USA; MT-10$13-\mathrm{CV})$ with the addition of $10 \%(\mathrm{v} / \mathrm{v})$ fetal bovine serum and $1 \%$ Pen Strep (Thermo Fisher Scientific, Waltham, MA, USA) at $37^{\circ} \mathrm{C}$ in a $5 \% \mathrm{CO}_{2}$ humidified atmosphere.
Bone marrow-derived macrophage culture All animal work was approved by the Vanderbilt University Institutional Animal Care and Use Committee. Bone marrowderived macrophages (BMDMs) were made by harvesting bone marrow from wild-type and NF- $\kappa \mathrm{B}$ green fluorescent protein (GFP)-luciferase (NGL) reporter transgenic mice on an FVB background. ${ }^{41}$ Cells from NGL mice produce a luciferase/GFP fusion protein as a readout of total NF- $\kappa B$ activation: activity of either the classical or alternative pathway induces expression of a GFP-luciferase reporter protein. The medium for these cells contained 10\% (v/v) fetal bovine serum, 1\% Pen Strep (Thermo Fisher Scientific), $5 \%$ heat-inactivated horse serum (Thermo Fisher Scientific), 1\% MEM nonessential amino acid mixture (Sigma-Aldrich Co., St Louis, MO, USA), and $50 \mu \mathrm{M}$ 2-mercaptoethanol (Sigma-Aldrich Co.) and was supplemented with media from L-129 fibroblasts as a source of macrophage colony stimulating factor (M-CSF). ${ }^{24}$ The bone marrow was cultured for 6 days in the M-CSF-supplemented medium, and the resultant BMDMs were scraped from their plates and replated as necessary for further experiments.

\section{Luciferase activity readout in reporter cells}

For cells producing luciferase as a readout of total NF- $\kappa \mathrm{B}$ activation, the Promega luciferase assay system with reporter lysis buffer was used to measure luciferase activity. Plated cells were frozen in $1 \times$ reporter lysis buffer, then subjected to a thaw-freeze-thaw cycle before being scraped from the plates, and centrifuged at 13,000 rpm for 4 minutes. Twenty microliters of the supernatant was added to $100 \mu \mathrm{L}$ of the luciferin substrate, and the resulting luminescence was measured to determine luciferase activity.

\section{Effects of tumor necrosis factor- $\alpha$ stimulation on BMDMs}

In order to induce NF-KB activation in macrophages, NGL BMDMs were stimulated with $0.01-1,000 \mathrm{ng} / \mathrm{mL}$ of tumor necrosis factor- $\alpha$ (TNF- $\alpha$ ) (PeproTech, Rocky Hill, NJ, US) for 6 hours. After 6 hours, NF-кB activation was assessed by the luciferase assay. For subsequent experiments, including TNF- $\alpha$ stimulation, $10 \mathrm{ng} / \mathrm{mL}$ concentrations were used. To assess mRNA changes following TNF- $\alpha$ stimulation, wildtype BMDMs were plated in six-well plates at a density of $2,000,000$ cells/well $\left(\sim 210,000\right.$ cells $\left./ \mathrm{cm}^{2}\right)$. Each sample was taken from a different mouse, for a total of three biological replicates, with three experimental replicates per biological replicate. The cells were stimulated for 6 hours with TNF- $\alpha$ $(10 \mathrm{ng} / \mathrm{mL})$. After stimulation, mRNA was collected from 
the cells for quantitative real-time polymerase chain reaction (qRT-PCR). The effect of TNF- $\alpha$ stimulation on the macrophages was analyzed by determining the changes in mRNA for the NF- $\kappa B$ pathway proteins IKK $\beta$ and p100/p52 as well as the mRNA for CCL3, an inflammatory cytokine, and the mRNA for IL-10, an immunoinhibitory cytokine (qRT-PCR procedure and primer sequences are detailed later).

\section{RNA preparation and $q R T-P C R$}

mRNA was extracted from cells using RNeasy kit (Qiagen NV, Venlo, the Netherlands), and DNA was removed from the samples using DNA-free kit (Thermo Fisher Scientific). cDNA was prepared from the isolated mRNA using dNTPs from Hoffman-La Roche Ltd., Basel, Switzerland, and random hexamers and superscript II reverse transcriptase were from Thermo Fisher Scientific. qRT-PCR was performed with SYBR green real-time PCR master mix (Thermo Fisher Scientific) using Step One Plus real-time PCR systems hardware and software (Thermo Fisher Scientific). The Step One Plus software was used to automatically calculate optimized baseline and threshold values. Differences in cDNA levels were calculated using the $\Delta \Delta \mathrm{Ct}$ method with glyceraldehyde 3-phosphate dehydrogenase as an internal control. The sequences used for qRT-PCR are summarized in Table 1.

\section{Screening effective siRNA sequences against NF- $\kappa B$ with Lipofectamine}

Several siRNA sequences against NF- $\kappa \mathrm{B}$ proteins were purchased from Thermo Fisher Scientific. The siRNA targets and their serial numbers are summarized in Table 2. The siRNAs were complexed with Lipofectamine and delivered to NGL BMDMs (12-well plates, 300,000 cells/well $\left[\sim 80,000\right.$ cells $\left./ \mathrm{cm}^{2}\right]$, four samples per condition) for 24 hours at an siRNA concentration of $10 \mathrm{nM}$. The most successful sequences were then used at $50 \mathrm{nM}$ and delivered to NGL BMDMs using both Lipofectamine and MnNPs.

\section{DNA and siRNA delivery to macrophages by MnNPs}

Wild-type BMDMs were cultured in normal media or in media containing IL-4 (10 ng/mL) (PeproTech) for 72 hours. IL-4 stimulation has been reported to increase mannose receptor presence on the cell surface. ${ }^{42}$ The cells were then plated in 96-well plates at a density of 50,000 cells/well $\left(\sim 350,000\right.$ cells $\left./ \mathrm{cm}^{2}\right)$. A 21-base pair, Cy3-labled DNA sequence was purchased from Sigma-Aldrich Co. for complexation with MnNPs. The sequence was designed to have the same base pair order and charge characteristics as the scrambled siRNA sequence from Thermo Fisher Scientific. To form nanoparticle-siRNA complexes, mannosylated endosomal escape polymers were synthesized as previously described ( $4 \mathrm{mg} / \mathrm{mL}$ in aqueous solution). ${ }^{37,38}$ For complexation with the polymer, all nucleotides were diluted to $50 \mu \mathrm{M}$ in sterile nuclease-free water. The nucleotides were mixed with the polymer solution at a ratio of $160 \mathrm{ng}$ of MnNP polymer per pmol of siRNA and allowed to form complexes at room temperature for 1 hour prior to use. For both studies, the effects of the siRNA on total NF- $\kappa B$ activity were assessed by luciferase assay following TNF- $\alpha$ stimulation of the cells. The Cy3_DNA (50 $\mu \mathrm{M}$ solution) was complexed with MnNPs or OHNPs, and the complexes were delivered to BMDMs. Cy3 fluorescence was measured at 0.5 hour, 1 hour, 3 hours, 5 hours, 10 hours, and 18 hours by washing the cells with phosphate-buffered saline (PBS) three times and then measuring fluorescence with a Tecan Infinite M1000-Pro plate reader as a measure of the particle uptake. Another set of BMDMs were plated as described earlier, and the Cy3_DNA sequence was delivered to the cells using either Lipofectamine or MnNPs with a 20-hour transfection time. These samples were measured for fluorescence with the Tecan Infinite M1000-Pro plate reader and imaged using a Nikon Eclipse Ti microscope. The total number of Cy3-positive cells was counted, and the percentage of $\mathrm{Cy} 3$-positive cells was determined.

Table I qRT-PCR primer sequences

\begin{tabular}{|c|c|c|}
\hline Gene & Forward sequence $\left(5^{\prime}-3^{\prime}\right)$ & Reverse sequence $\left(5^{\prime}-3^{\prime}\right)$ \\
\hline GAPDH & TGAGGACCAGGTTGTCTCCT & СCCTGTTGCTGTAGCCGTAAT \\
\hline $\operatorname{I\kappa B} \alpha$ & TGAAGGACGAGGAGTACGAGC & TTCGTGGATGATTGCCAAGTG \\
\hline pl00 & GCTTCTCAGCTTTCCTTCGAGCTA & GCAAATAAACTTCGTCTCCACCGC \\
\hline IKK $\beta$ & GCTGGAGCAGAGAAATGTCAGAGT & CTCAGGAACAATCAAAGCGTGCAG \\
\hline CXCL9 & GTGGTGAAATGGAAAGATCAGGGC & AAGAGAGAAATGGGTTCCCTGGAG \\
\hline IL-10 & АССTGСTCСАСTGCСTTGCT & GGTTGCCAAGCCTTATCGGA \\
\hline CD206 & CAAGGAAGGTTGGCATTTGT & CCTTTCAGTCCTTTGCAAGC \\
\hline CCL3 & TGCCCTTGCTGTTCTTCTCT & GATGAATTGGCGTGGAATCT \\
\hline
\end{tabular}

Abbreviations: qRT-PCR, quantitative real-time polymerase chain reaction; GAPDH, glyceraldehyde 3-phosphate dehydrogenase; IL-I0, interleukin-I0. 
Table 2 siRNA targets and serial number of siRNA sequences purchased from Thermo Fisher Scientific (Waltham, MA, USA)

\begin{tabular}{ll}
\hline siRNA target & Serial number \\
\hline Scrambled sequence & 4390846 \\
Luciferase & AM4629 \\
IKK $\beta(A)$ & $s 68 I 73$ \\
IKK $\beta(B)$ & $s 68 I 74$ \\
IKK $\beta(C)$ & $s 68 I 75$ \\
P52/p I00 (A) & $s 70545$ \\
p52/p I00 (B) & $s 70546$ \\
p52/p I00 (C) & $s 70547$ \\
p65 (A) & $s 72857$ \\
P65 (B) & $s 72858$ \\
P65 (C) & $s 72859$ \\
IKB $\alpha$ & $s 70549$ \\
\hline
\end{tabular}

Abbreviation: siRNA, small interfering RNA.

\section{Effects of IKB $\alpha$ knockout macrophages on cocultured tumor cells}

Immortalized murine macrophages from I $\mathrm{BB} \alpha$ knockout mice were incubated with GFP-expressing ID8 murine ovarian tumor cells on glass slides. ${ }^{39,43,44}$ The coculture was fixed and stained after 3 days of incubation. The samples were fixed in $4 \%$ paraformaldehyde for 30 minutes and permeabilized in $0.4 \%$ Triton X-100 for 10 minutes. Next, the slides were washed for 10 minutes two times in Trisbuffered saline (TBS) with $0.05 \%$ Tween 20 . They were then washed with TBS for 5 minutes and blocked for 1 hour in blocking buffer $(0.01 \mathrm{M}$ Tris- $\mathrm{HCl}, \mathrm{pH} 7.4,2 \%$ bovine serum albumin, $2 \%$ normal goat serum). The samples were then incubated with primary tubulin antibodies in blocking buffer overnight at $4^{\circ} \mathrm{C}$, washed three times in TBST (TBS + Tween), and incubated for 2 hours with secondary antibodies in the blocking buffer. After staining with secondary antibodies, the slides were washed three times with TBS containing $0.05 \%$ Tween 20 , then washed once in TBS, and then stained with Molecular Probes TO-PRO-3 (Thermo Fisher Scientific) for 15 minutes ( $1 \mu \mathrm{M}$ in TBS). The slides were washed with TBS and the coverslips mounted using Molecular Probes ProlongGold antifade reagent (Thermo Fisher Scientific). Images were acquired using an LSM 510 Meta confocal microscope in the Vanderbilt University Medical Center Imaging Core.

\section{Effect of $I \kappa B \alpha$ siRNA on total NF- $\kappa B$ activation in macrophages}

To investigate the possibility of activating the classical $\mathrm{NF}-\kappa \mathrm{B}$ pathway by knocking down the inhibitor of the

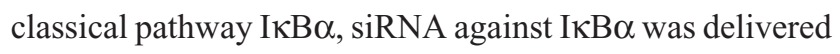
to NGL BMDMs in 12-well plates at $50 \mathrm{nM}$ for 24 hours using MnNPs. Free siRNA and empty MnNPs were also delivered separately as controls. Total NF- $\kappa \mathrm{B}$ activation was assessed at 6 hours, 12 hours, and 24 hours by luciferase assay. Wild-type BMDMs were plated in six-well plates at a density of 2,000,000 cells/well ( 210,000 cells $\left./ \mathrm{cm}^{2}\right)$. Each sample was taken from a different mouse, for a total of three biological replicates, with three experimental replicates per biological replicate. The cells were transfected using MnNPs for 24 hours with $\mathrm{I} \kappa \mathrm{B} \alpha$ or scrambled siRNA, with and without TNF- $\alpha$ stimulation. After transfection, mRNA was collected from the cells for qRT-PCR (as earlier).

\section{Statistical analysis}

Data are reported as the sample mean, and error bars represent one SD from the mean. Paired comparisons were made using a two-tailed $t$-test to determine significant differences between samples. For datasets where multiple experimental groups were compared to the control group, Dunnett's test was used to determine significant differences. For samples with multiple comparisons, analysis of variance was used to confirm significant differences within the groups; then post hoc analysis was performed using two-tailed $t$-tests. The probability for type I error in the post hoc analysis was reduced by minimizing the number of paired comparisons using a priori knowledge of the relationships between groups and selecting only the most pertinent comparisons.

\section{Results and discussion TNF- $\alpha$ stimulation of BMDMs}

It has been reported that BMDMs are a viable in vitro model for TAMs. ${ }^{7}$ BMDMs are made from myeloid progenitor cells harvested from femoral bone marrow and matured in media supplemented with M-CSF. In vivo, M-CSF is a potent macrophage-recruiting and maturation cytokine and is known to play a role in the recruitment of myeloid progenitors into tumors and maturing these cells into macrophages. ${ }^{45}$ After 6 hours of incubation of BMDMs in TNF- $\alpha$-treated media, total NF- $\kappa$ B activity increased in a dose-dependent manner as measured by luciferase readout as a proxy measure of NF- $\kappa \mathrm{B}$ activity (Figure 2A). These results were used to select a sensitive baseline of NF- $\kappa \mathrm{B}$ activation for subsequent assessments of activation suppression resulting from siRNA treatments. TNF- $\alpha$ stimulation of BMDMs was also confirmed by qRTPCR, which shows the expected increase in the inflammatory cytokine CCL3 and a decrease in the immunoinhibitory IL-10 
A

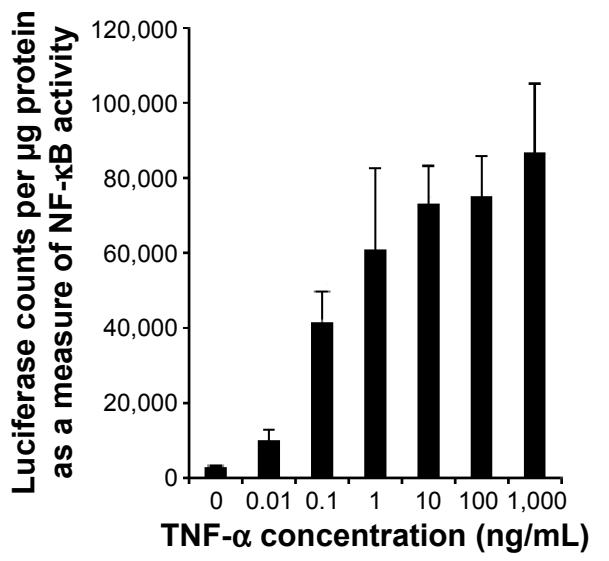

B

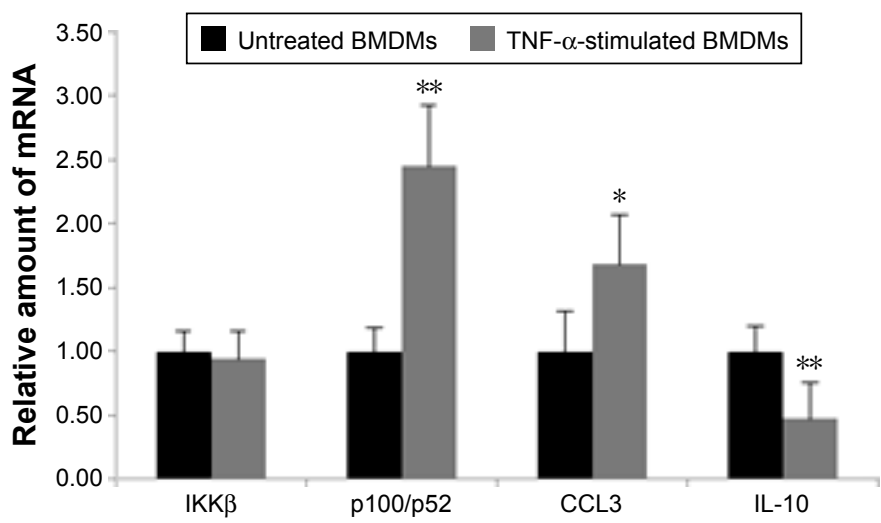

Figure 2 Activation of NF- $\kappa B$ in BMDMs by TNF- $\alpha$.

Notes: (A) Activation of NF-KB in BMDMs by TNF- $\alpha$ is dose dependent. (B) qRT-PCR of TNF- $\alpha$-stimulated BMDMs and unstimulated BMDMs. Activation is confirmed by significant increase in CCL3 mRNA and significant decrease in IL-10 mRNA. Levels of p 100/p 52 mRNA significantly increase following 6 hours of TNF- $\alpha$ stimulation, but the amount of IKK $\beta$ mRNA does not significantly increase. $* P<0.05$, $* * P<0.005$.

Abbreviations: NF- $\mathrm{kB}$, nuclear factor-kappaB; BMDM, bone marrow-derived macrophage; TNF- $\alpha$, tumor necrosis factor- $\alpha$; qRT-PCR, quantitative real-time polymerase chain reaction; $\mathrm{mRNA}$, messenger RNA; IL-I0, interleukin- I0.

(Figure 2B). While mRNA levels of IKK $\beta$ were not found to increase after stimulation, mRNA for the transcriptionally active p100/p52 protein significantly increased.

\section{Screening NF-kB-specific siRNA sequences for efficacy using Lipofectamine and MnNPs} In order to confirm that siRNA could knockdown NF- $\mathrm{BB}$ activity in macrophages, several sequences for IKK $\beta$, p52/p100, and p65 were screened in NGL BMDMs using Lipofectamine as the transfection agent. Luciferase siRNA was used as an additional control for the effect of direct knockdown of the reporter protein. Efficacious siRNA sequences were confirmed for the NF- $\kappa B$-related proteins shown in Figure 3A. Transfection with IKK $\beta$ siRNA significantly reduced the total NF- $\kappa \mathrm{B}$ activity by $\sim 40 \%$ for sequences $\mathrm{B}$ and C. Similar significant reduction in activation
A

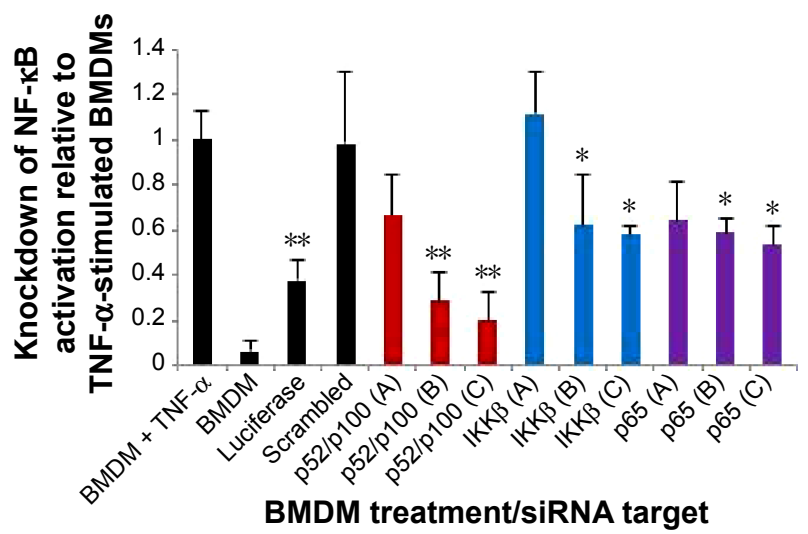

B

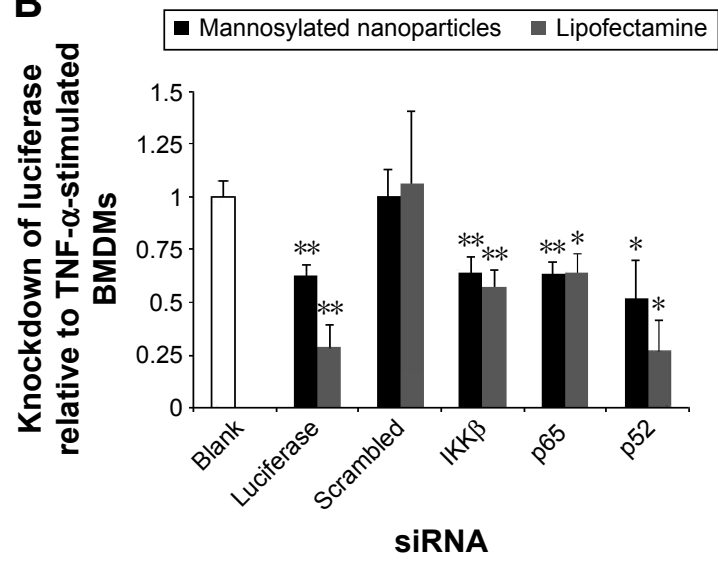

Figure 3 Lipofectamine and MnNP-delivered siRNA sequences knockdown NF-kB activation.

Notes: (A) Knockdown of total NF- $\kappa B$ by Lipofectamine-delivered siRNA sequences as measured by luciferase assay. The first bar represents data from BMDM samples stimulated with TNF- $\alpha$ without siRNA transfection and was used as a baseline for comparison. The bar labeled "BMDM" represents negative control BMDM samples that did not receive either TNF- $\alpha$ stimulation or siRNA transfection. All siRNA-transfected BMDMs were stimulated with $10 \mathrm{ng} / \mathrm{mL}$ TNF- $\alpha$ for 6 hours to activate the NF- $K B$ pathway. Three siRNA sequences for each NF- $K B$ pathway protein were used (designated $A, B$, and $C$ ). Single-factor ANOVA confirms significant differences within the dataset $(P<0.000$ I). $t$-Tests for significance compare the group of TNF- $\alpha$-stimulated BMDMs to each group of siRNA-transfected, TNF- $\alpha$-stimulated $B M D M s$. $* P \leq 0.05$, $* * P \leq 0.0$ I. (B) MnNP-delivered $50 \mathrm{nM}$ siRNA knockdown of total NF- $\kappa B$ activity is comparable to knockdown achieved by using Lipofectamine. All samples were stimulated with $10 \mathrm{ng} / \mathrm{mL}$ TNF- $\alpha$ following transfection. In addition to exhibiting efficacious delivery and knockdown characteristics, MnNPs are designed to be biocompatible both in vitro and in vivo. Dunnett's tests for significance compare TNF- $\alpha$-stimulated BMDMs (Blank, control) to siRNA transfected, TNF- $\alpha$-stimulated $B M D M s$. $* P \leq 0.05$, $* * P \leq 0.01$.

Abbreviations: NF- $\kappa B$, nuclear factor-kappaB; siRNA, small interfering RNA; BMDMs, bone marrow-derived macrophages; TNF- $\alpha$, tumor necrosis factor- $\alpha$; ANOVA, analysis of variance. 
$(40 \%-45 \%)$ was measured following transfection with p65 siRNA sequences B and C. This level of knockdown is consistent with siRNA knockdown of a single pathway, which would leave the unaffected pathway free to normally respond to stimuli. It is interesting to note that knockdown of the alternative pathway with p52/p100-specific siRNA sequences ( $\mathrm{B}$ and $\mathrm{C}$ ) resulted in a $70 \%-80 \%$ decrease in total NF- $\kappa \mathrm{B}$ activity following TNF- $\alpha$ stimulation. This result is consistent with the existence of crosstalk between the two NF- $\kappa B$ signaling pathways, or that TNF- $\alpha$ stimulation of NF- $\kappa \mathrm{B}$ activation in these cells was driven largely by the alternative pathway, and the siRNA sequences for this pathway were very effective.

It is known that products of one NF- $\kappa B$ pathway can modulate another, in particular, the TNF family of proteins. ${ }^{3}$ Knocking down activity of the alternative pathway may also affect the classical pathway via inhibition of cytokine production that could crosstalk to stimulate that pathway. $\mathrm{NF}-\kappa \mathrm{B}$ activation can be accomplished with protein dimers other than p50:p65 and p52:RelB. Since it is possible that knockdown of p52 suppresses the formation of p52:p65 heterodimers, it is also possible that reduction of p52 activates a compensatory mechanism and results in more production of p105, which is degraded to p50, although there is currently no direct evidence for this mechanism. An increase in p50 could result in the formation of p50 homodimers, which are known to inhibit classical activation. ${ }^{46}$

To compare the transfection ability of MnNPs with Lipofectamine, $50 \mathrm{nM}$ siRNA was delivered to NGL BMDMs for 24 hours by MnNPs or Lipofectamine; knockdown of total NF- $\mathrm{KB}$ activity was analyzed by luciferase assay following TNF- $\alpha$ stimulation. The most successful sequence for each protein from Figure $3 \mathrm{~A}$ was used. MnNP-mediated siRNA knockdown of total NF- $\kappa \mathrm{B}$ activity was similar to Lipofectamine-mediated knockdown (Figure 3B). Total $\mathrm{NF}-\kappa \mathrm{B}$ activity was significantly decreased upon MnNP delivery of siRNA sequences. The average knockdown of total NF- $\kappa \mathrm{B}$ activity by Lipofectamine-delivered siRNA was less than the knockdown from $10 \mathrm{nM}$ siRNA shown in Figure $3 \mathrm{~A}$. It is possible that this decrease in efficacy is due to an increase in cytotoxicity associated with increasing the amounts of Lipofectamine combined with TNF- $\alpha$ stimulation, as suggested previously. ${ }^{38}$

\section{Comparing the uptake of MnNPs with untargeted particles and Lipofectamine}

We have previously shown that uptake of MnNPs can be reduced by introducing free mannose during transfection, which competes with the MnNPs for uptake by the macrophage mannose receptor. ${ }^{37}$ To further investigate the potential for specific delivery to TAMs, untargeted OHNPs or MnNPs loaded with Cy3-labeled dsDNA were delivered to BMDMs for 18 hours. Two different populations of BMDMs were used: untreated BMDMs and BMDMs stimulated with IL-4 to increase mannose receptor production. ${ }^{42}$ Particle uptake by BMDMs was measured at various time points by measuring Cy3 fluorescence in the BMDMs. In IL-4stimulated macrophages, uptake of MnNPs is significantly increased as compared to that of MnNPs in unstimulated macrophages (Figure 4A and B). Uptake of OHNPs was not significantly different between the two groups of cells. This result indicates that the mannose ligand on the surface of the MnNPs is mediating enhanced uptake, which is specific for macrophages that have undergone phenotypic differentiation by IL-4.

Although IL-4-stimulated BMDMs are reported to have increased mannose receptor production, unstimulated BMDMs also express this receptor at their surface. This explains why, even at earlier time points, MnNP uptake is enhanced relative to OHNP uptake in both IL-4-stimulated and -unstimulated BMDMs. Significant uptake of MnNP occurs as early as 30 minutes after administration to IL-4stimulated BMDMs. This rapid uptake is consistent with endosomal uptake of the particles, presumably mediated by the mannose receptor. Some modest nonspecific uptake is also evident. It is likely that some particles are phagocytized by the macrophages or taken up via other nonspecific endosomal pathways.

A final experiment investigating the mechanism of MnNP delivery to macrophages compared 20-hour MnNP delivery to Lipofectamine delivery. Both transfection agents were labeled with Cy3_dsDNA. After 20 hours of incubation, Cy3 fluorescence was measured as an indicator of particle uptake, and the percentage of $\mathrm{Cy} 3$-positive cells was determined from fluorescent and bright-field images of the cells. Transfection with MnNPs resulted in significantly more uptake of Cy3labeled nucleotide than transfection with Lipofectamine (Figure 4C). Furthermore, Lipofectamine transfects a larger population of cells with Cy3-labeled nucleotides, but the total fluorescence delivered is approximately half of that delivered by MnNPs (Figure 4D). Compared to Lipofectamine, MnNPs strongly transfect a smaller subset of macrophages. This is consistent with the mechanism of MnNP transfection as a more targeted delivery to cells expressing the corresponding surface receptor. This result, combined with our previous report that the uptake of MnNP is mannose dependent, is 

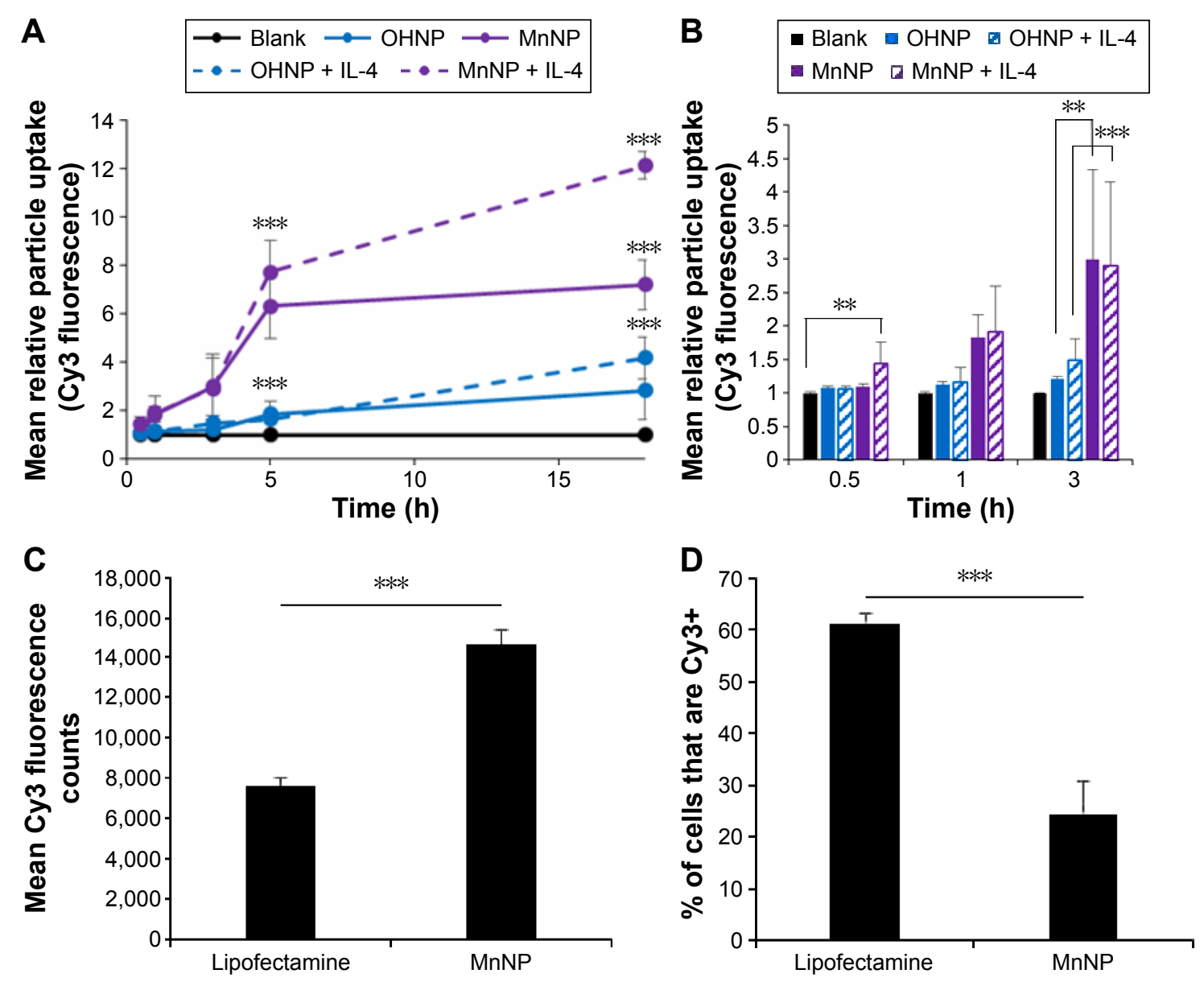

Figure 4 Nanoparticle uptake time course in IL-4-stimulated and -unstimulated BMDMs.

Notes: Analysis of variance indicates significant differences within the dataset $(P<0.00 \mathrm{I})$. (A) Uptake of MnNPs in IL-4-stimulated BMDMs was significantly greater than the uptake in unstimulated BMDMs after 18 hours. Uptake of MnNPs under both conditions was significantly greater than the uptake of OHNPs after 5 hours and 18 hours. (B) Earlier time points of nanoparticle uptake are highlighted. Uptake of MnNPs occurs as early as 30 minutes after administration. Uptake of MnNPs is significantly greater than uptake of OHNPs after I hour. (C) Transfection of BMDMs with MnNPs resulted in significantly more uptake of Cy3-labeled nucleotide than transfection with Lipofectamine after 20 hours. (D) MnNPs transfect a smaller subset of cells than Lipofectamine. Lipofectamine transfects a larger population of cells with Cy3-labeled nucleotide, but the total fluorescence delivered is approximately half of that delivered by MnNP. Unpaired, two-tailed $t$-tests for significant differences in group averages were performed between multiple experimental groups. $* * P \leq 0.05$, $* * * P \leq 0.001$.

Abbreviations: IL-4, interleukin-4; BMDMs, bone marrow-derived macrophages; MnNP, mannosylated endosomal escape nanoparticle; OHNP, hydroxyl-capped nanoparticle; h, hours.

consistent with MnNPs targeting a subset of macrophages with greater amounts of mannose receptor. Macrophages (and TAMs) with a tissue remodeling/immunoinhibitory phenotype have increased mannose receptor production. This effect is so pronounced that the presence of high levels of mannose receptor in macrophages is a commonly used indicator for this macrophage phenotype. Therefore, this result enhances our previous work showing enhanced uptake of MnNPs by TAMs in vivo. ${ }^{38}$

\section{Target protein selection for strategic manipulation of NF- $\kappa B$ to produce therapeutically relevant changes in TAM phenotype}

Our screen of siRNA sequences for NF- $\kappa$ B proteins confirms knockdown of total NF- $\mathrm{B}$ activity by MnNP-delivered
siRNA. Although siRNA sequences for IKK $\beta$, p65, and p52 all resulted in significant knockdown, it is important to establish whether these proteins will be efficacious targets or not. Although p65 is implicated in producing smoldering inflammation in the tumor microenvironment, it is also responsible for survival signaling in macrophages. Therefore, p65 may not be an optimum target because knocking down p65 could potentially induce apoptosis in the macrophages being targeted for phenotypic modification. . $^{474}$

Viable targets for therapeutic siRNA knockdown should ideally also express increased amounts of the target mRNA while in the pathological state. qRT-PCR of TNF- $\alpha$ stimulated BMDMs indicates that levels of p52 mRNA are increased upon exposure to TNF- $\alpha$, making p52 a viable target for knocking down alternative NF- $\kappa \mathrm{B}$ activity in TAMs. However, levels of IKK $\beta$ do not significantly increase 
(Figure 2B). It is known that the classical NF- $\mathrm{BB}$ pathway is rapidly activated within minutes of stimulation, while alternative activation is more gradual..$^{27,49,50}$ If there is an increase in IKK $\beta$ mRNA, it is possible that the increase is rapidly induced and then rapidly degraded. Another alternative is that there is already enough IKK $\beta$ protein active in the cell to activate enough p50:p65 homodimers and induce a classical NF- $\kappa$ B response; increased production of IKK $\beta$ may not be necessary. Regardless of the reason, this lack of increase in IKK $\beta$ mRNA makes it a poor target for siRNA-mediated knockdown. In addition, there are significant non-NF- $\kappa B$ functions of IKK $\beta$, and knocking down this protein could potentially have off-target effects. ${ }^{3}$

As discussed earlier, neither IKK $\beta$ nor $p 65$ is an attractive target for siRNA-mediated knockdown to achieve a reduction in the smoldering inflammation produced by TAMs. However, decreasing the smoldering inflammation from these cells is not the only therapeutic option. If the full inflammatory potential of the TAMs could be reactivated, these cells could promote a potent immune response at the site of the tumor by releasing inflammatory cytokines and inducing apoptosis as well as by recruiting cytotoxic immune cells of innate and adaptive immune system. This effect could be achieved by strongly activating the classical NF- $\kappa B$ pathway in TAMs.

Although the strategy to deliver siRNA with MnNPs was initially designed to knockdown NF- $\kappa$ B activity, it should theoretically be able to activate the classical pathway as well. Activation of transcriptional pathways by siRNA has been reported before, but only as an undesirable, off-target side effect. Because the I $\kappa \mathrm{B} \alpha$ protein inhibits activation of the classical pathway, knocking down this protein could potentially increase classical NF- $\kappa$ B activation. This proposed activation of a key transcriptional pathway is a novel approach to manipulating cell phenotype for immunoengineering. To test this possibility, NGL BMDMs were transfected with MnNP-delivered siRNA against I $\mathrm{B} \alpha$ for 24 hours, and total $\mathrm{NF}-\kappa \mathrm{B}$ activation was measured at multiple time points during transfection. Delivery of $\mathrm{I} \kappa \mathrm{B} \alpha$ siRNA by MnNPs induced significant activation of NF- $\kappa B$ without any other source of stimulation (Figure 5). The particle-delivered siRNA increased the total NF- $\kappa$ B activity in the macrophage population 2.3-fold; however, this measurement was taken from the combined lysate of the entire macrophage population and, as Figure 4D shows, the MnNPs transfect $\sim 25 \%$ of the macrophages in the population. The effect of transfection in the targeted cells is presumably diluted by the presence of untransfected cells. When the $75 \%$ untransfected population is taken into account in the luciferase assay results reported in

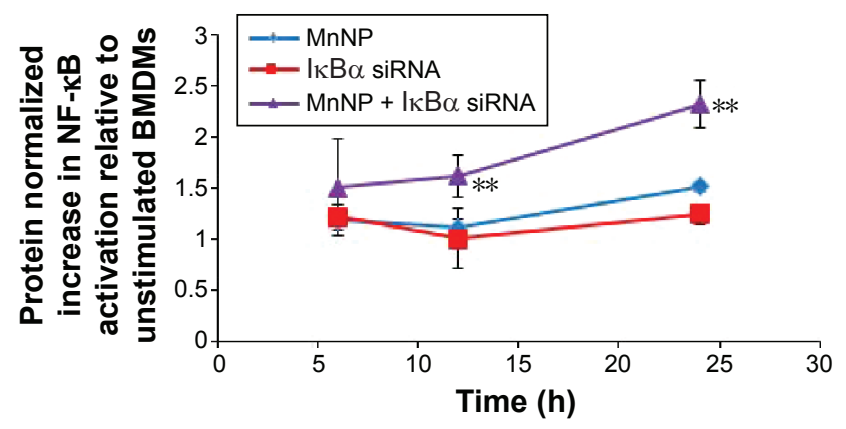

Figure 5 Activation of NF- $\kappa B$ in NGL BMDMs by MnNP delivery of $I \kappa B \alpha$ siRNA without any other form of stimulation or activation.

Notes: NF- $\mathrm{KB}$ activity is significantly increased as early as 12 hours following transfection with $I \kappa B \alpha$ by $M n N P s$ and has more than doubled 24 hours after transfection $(* * P \leq 0.001)$. There is some small activation caused by delivery of unloaded MnNP polymer after 24 hours, but this activation is significantly less than that mediated by delivery of both MnNPs and $1 \kappa B \alpha(P=0.005)$.

Abbreviations: NF- $\kappa B$, nuclear factor-kappaB; NF- $\kappa B$ GFP-luciferase NGL; GFP, green fluorescent protein; BMDMs, bone marrow-derived macrophages; $\mathrm{MnNP}$, mannosylated endosomal escape nanoparticle; siRNA, small interfering RNA; $h$, hours.

Figure 5, the actual increase in total NF- $\kappa \mathrm{B}$ activity solely in the transfected population is estimated to be approximately ninefold.

This work identifies a novel approach to therapeutic RNAi: using protein knockdown to suppress expression of an inhibitor and increase activation of a transcriptionally active pathway. Knocking down the inhibitor of the classical NF- $\kappa$ B pathway increases total NF- $\kappa B$ activity, but it is important to understand whether this knockdown is physiologically and therapeutically relevant. In order to understand what effect I $\mathrm{K} \mathrm{B} \alpha$ knockdown in macrophages might have

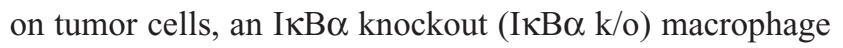
line was cocultured with GFP expressing ovarian tumor cells (ID8 cell line) for 3 days, and the coculture was imaged at day 1 and day 3. The I $\mathrm{KB} \alpha \mathrm{k} / \mathrm{o}$ macrophage/ID8 tumor cell coculture is compared to a wild-type macrophage line, also at 3 days cocultured with ID8 cells (Figure 6). After 3 days, the wild-type macrophages exist in stable coculture with the tumor cells and there are no overt morphological signs of cytotoxicity in either cell type. However, the I $\mathrm{B} \alpha$ $\mathrm{k} / \mathrm{o}$ macrophages appear to mediate tumor cell cytotoxicity presumably via extracellular lysis of the tumor cells such that only fragments of the tumor cells are left. ${ }^{51,52}$ This result suggests that activation of NF-kappaB via deletion of the $\mathrm{I} \kappa \mathrm{B} \alpha$ inhibitor can induce tumor cytotoxic functions.

\section{qRT-PCR of BMDM transfected with NF- $\kappa B$-specific siRNA sequences by MnNPs}

To determine whether interaction with the MnNP transfection agent and delivery of control siRNA by MnNPs results in any significant expression of relevant genes, MnNPs were used to transfect BMDMs with a scrambled siRNA sequence. 

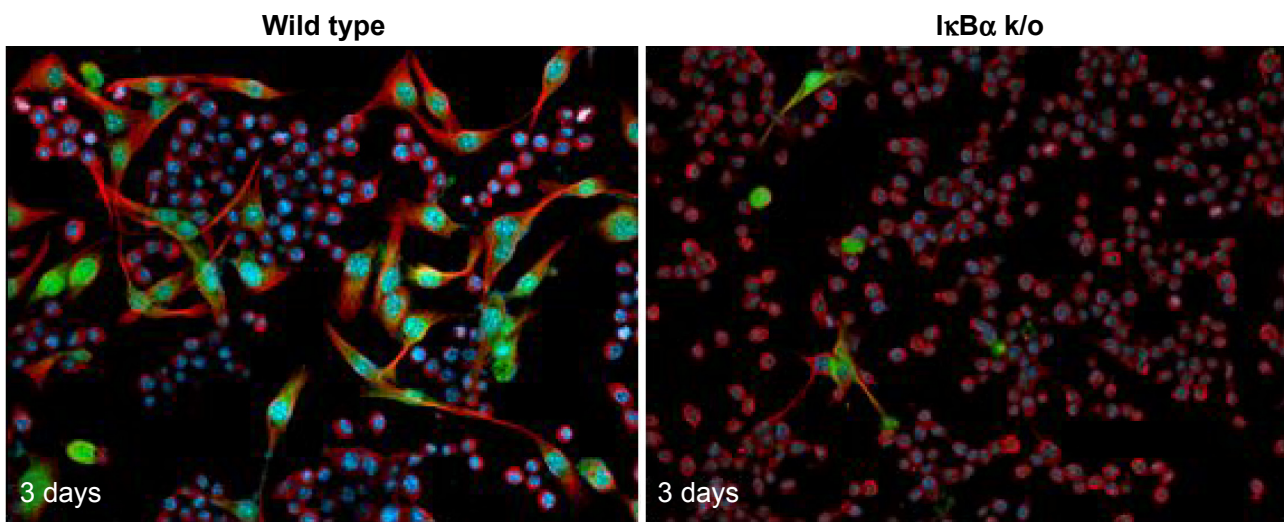

ID8 tumor cells, tubulin, TO-PRO-3 (nuclei)

Figure 6 Coculture of WT and IKB $\alpha$ k/o macrophages with ID8 tumor cells.

Notes: WT macrophages in left panel (small, circular cells; no green) cohabit with GFP-producing ID8 tumor cells (green, spindle shaped). However, macrophages with increased

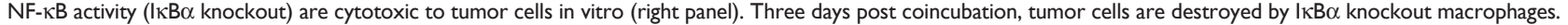
Abbreviations: WT, wild type; GFP, green fluorescent protein; NF- $\mathrm{B}$, nuclear factor-kappaB.

Figure 7 shows that there are no significant differences between macrophages transfected with scrambled siRNA sequences and untransfected macrophages for mRNA for IאB $\alpha$, p52, IL-10, or CXCL9 (a T-cell recruiting cytokine). There is a significant increase in CD206 (mannose receptor) upon uptake of the MnNPs. This is consistent with an expected increase in receptor production following CD206 binding events and activation that contributes to the rapid recycling of this receptor..$^{53,54}$

To assess the potential for delivery of I $\mathrm{KB} \alpha$ siRNA by MnNPs to induce immunostimulatory and antitumor effects,

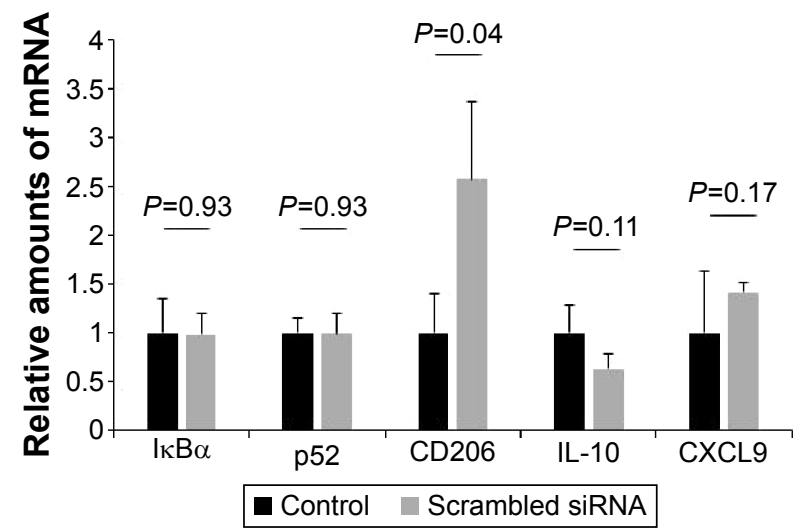

Figure 7 qRT-PCR of scrambled siRNA-transfected BMDMs.

Notes: There is no significant decrease in mRNA levels between the two groups for $1 \kappa B \alpha, p 52, I L-10$, and CXCL9. There is a significant increase in CD206 mRNA following culture with MnNPs loaded with a scrambled siRNA sequence. This is consistent with previous reports that activation and endosomal transport of the mannose receptor increases mannose receptor production in macrophages. Twotailed $t$-tests were used to determine significant differences between control and siRNA-transfected BMDMs.

Abbreviations: qRT-PCR, quantitative real-time polymerase chain reaction; siRNA, small interfering RNA; BMDMs, bone marrow-derived macrophages; mRNA, messenger RNA; IL-10, interleukin-10; MnNP, mannosylated endosomal escape nanoparticle.
mRNA from transfected BMDMs was analyzed by qRTPCR. mRNA levels for $I \kappa B \alpha$ are significantly decreased following transfection with I $\kappa \mathrm{B} \alpha$ siRNA, indicating successful knockdown at the mRNA level of IאB $\alpha$ (Figure 8A). Effects on the mRNA levels of relevant cytokines in the cancer microenvironment that are produced by macrophages were also quantified. I $\mathrm{B} \alpha \mathrm{RNAi}$ increases the amount of CXCL9 mRNA in macrophages to a level that is equivalent to levels of CXCL9 mRNA in TNF- $\alpha$-stimulated macrophages (Figure 8B). Furthermore, the combination of I $\mathrm{B} \alpha \alpha$ siRNA and TNF- $\alpha$ acts in an additive manner, resulting in significantly more CXCL9 mRNA than by either treatment alone. CXCL9 is a chemotactic signal that recruits $\mathrm{CD} 8^{+} \mathrm{T}$-cells and NK cells, and increasing CXCL9 in the tumor microenvironment has been shown to enhance antitumor immunity in murine breast cancer models. ${ }^{55,56}$ It has also been reported that intermediate CXCL9 signaling is necessary for T-cells to respond to other recruitment signals, such as IL-12. ${ }^{57}$ Therefore, the increase in expression of CXCL9 indicates that knockdown of I $\mathrm{BB} \alpha$ in TAMs could result in increased recruitment of activated cytotoxic cells of the innate and adaptive immune systems to the tumor microenvironment. The recruitment of T-cells to solid tumors has been the major focus of many efforts to induce tumor immunity in several types of cancer. ${ }^{1,2,58}$ Increased recruitment of T-cells by modified macrophages in the tumor would be another potential method of activating adaptive tumor immunity.

MnNP-delivered I $\mathrm{B} \alpha$ siRNA also decreases levels of phenotypic markers, which indicates a protumor immunosuppressive macrophage phenotype. Increased levels of the mannose receptor CD206 in macrophages indicate an alternatively 

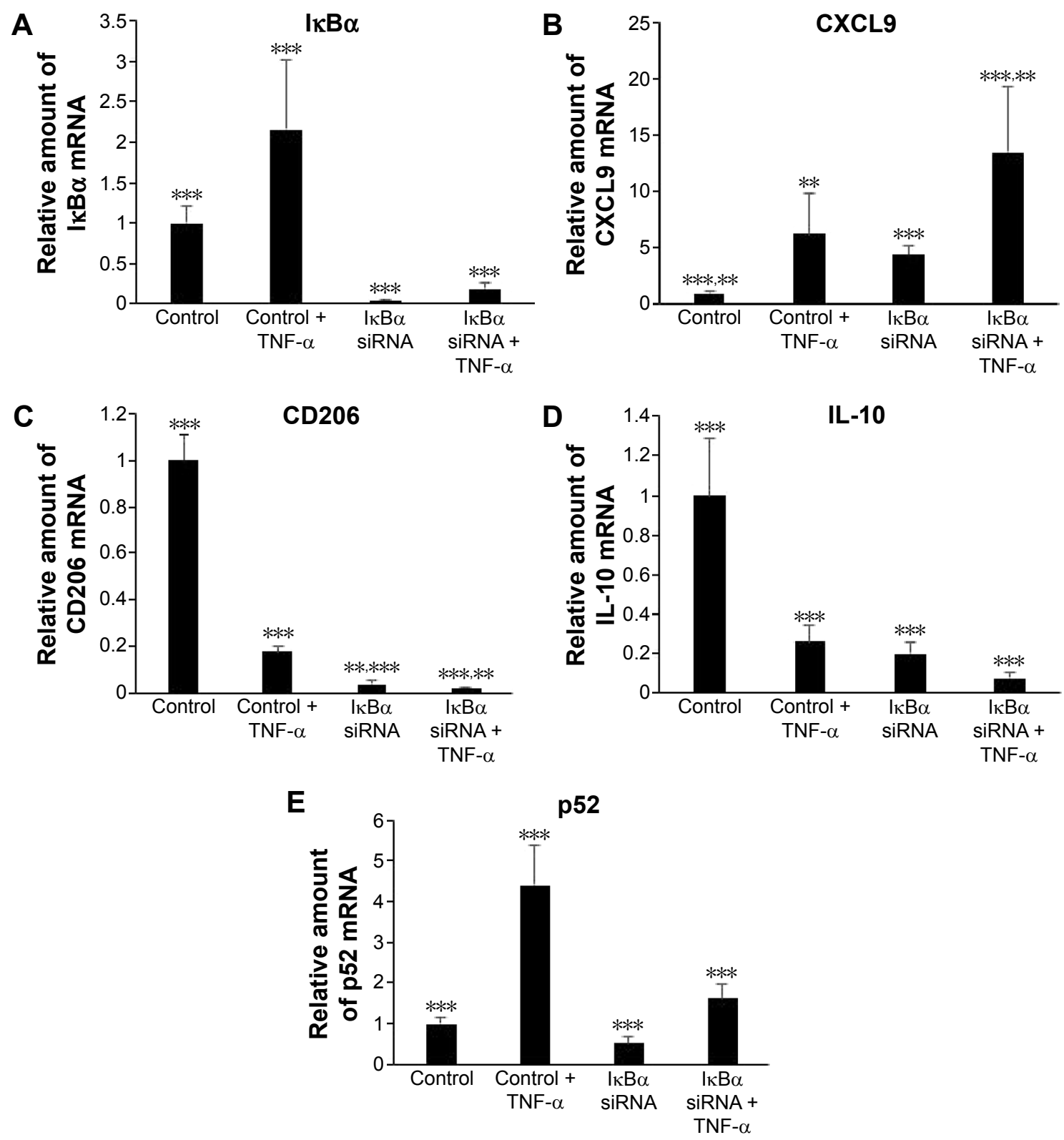

Figure 8 qRT-PCR of IKB $\alpha$ siRNA-transfected BMDM.

Notes: The measured mRNA corresponds to the protein indicated as the panel title and on the vertical axis. In all cases, ANOVA indicates the presence of significant


significantly reduced by $I \kappa B \alpha$ siRNA. (B) I $\mathrm{K} B \alpha$ siRNA increases mRNA for the T-cell recruitment cytokine CXCL9. The increase in CXCL9 mRNA by transfection alone is not significantly different from the increase caused by TNF- $\alpha$ alone. (C) IKB $\alpha$ siRNA decreases mRNA for the mannose receptor CD206, an M2 and TAM phenotype marker. The combination of TNF- $\alpha$ and IKBa siRNA significantly potentiates the decrease in CD206 mRNA. (D) IKB $\alpha$ siRNA decreases mRNA for IL-I0, an immunosuppressive cytokine. The decrease in IL-10 mRNA by transfection alone is not significantly different from that caused by TNF- $\alpha$ alone, but the combination results in less IL- 10 mRNA than by either condition alone. (E) I $\mathrm{kB} \alpha$ siRNA decreases mRNA for $\mathrm{p} 52$. TNF- $\alpha$ stimulation of macrophages increases levels of $\mathrm{p} 52$ mRNA: 552 is a viable target for mRNA level knockdown. Transfection with $\mathrm{I} \mathrm{B} \alpha$ siRNA reduces the increase in $\mathrm{p} 52 \mathrm{mRNA}$ caused by TNF- $\alpha$, indicating potentially beneficial crosstalk between the two pathways, which could be leveraged to act synergistically toward altering the TAM phenotype to an antitumor phenotype. $* * P \leq 0.0$ I, $* * * P \leq 0.005$.

Abbreviations: qRT-PCR, quantitative real-time polymerase chain reaction; siRNA, small interfering RNA; mRNA, messenger RNA; BMDM, bone marrow-derived macrophage; ANOVA, analysis of variance; TNF- $\alpha$, tumor necrosis factor- $\alpha$; TAM, tumor-associated macrophage; IL-I0, interleukin-I0.

activated phenotype and/or a TAM phenotype. ${ }^{34,35}$ Both TNF- $\alpha$ and I $\kappa \alpha$ siRNA decrease mRNA for CD206 in macrophages (Figure $8 \mathrm{C}$ ). The combination of the two treatments also significantly decreases CD206 mRNA. This effect is particularly important because the mannose receptor is the target of the mannose ligand on the MnNP surface.
Transfecting macrophages with IкB $\alpha$ siRNA effectively decreases the amount of the target on the macrophage surface. This effect could ensure that only macrophages with a strong TAM phenotype, cells with more CD206 on their surface, have enhanced endosomal uptake of the particles. This selflimiting uptake contributes to preferential targeting of siRNA 
only in alternatively activated macrophages, potentially suppressing off-target effects. Transfection would then alter the phenotype of the macrophage toward classical immune activity, reducing the amount of CD206 on the cell surface and preventing further unnecessary transfection. The MnNPs would then be free to transfect the remaining resident macrophages with high levels of CD206 or recently recruited macrophages with a TAM phenotype. MnNPs could also act as a surveillance mechanism if there are particles retained extracellularly in the tumor, retransfecting macrophages if they begin to readopt a TAM phenotype and express CD206 at their surface.

I $\kappa \mathrm{B} \alpha$ siRNA decreases the amount of IL-10 mRNA in macrophages to a level that is equivalent to levels of IL-10 mRNA in TNF- $\alpha$-stimulated macrophages, and the combination of I $\kappa \mathrm{B} \alpha$ siRNA and TNF- $\alpha$ results in significantly less IL-10 mRNA than by either treatments alone (Figure 8D). IL-10 is a potent immunosuppressive cytokine and is implicated in creating the TAM phenotype by paracrine signaling from tumor cells, by other TAMs, and by autocrine signaling. ${ }^{12,59}$ IL-10 has been reported to specifically inhibit the classical NF- $\kappa \mathrm{B}$ pathway by increasing the amount of cytoplasmic p105 and p50:p50 homodimers and by reducing p65 translocation into the nucleus. ${ }^{60,61}$ Treatment of macrophages with IL-10 reduces classical NF- $\kappa B$ responsiveness to stimulating cytokines such as lipopolysaccharide and TNF- $\alpha$ by reducing nuclear translocation of p65:p50 homodimers, which are responsible for much of the classic inflammatory response governed by NF- $\kappa \mathrm{B}$ and by increasing translocation of p50:p50 homodimers that strongly inhibit the classical immune response. ${ }^{62}$ In many cases, p50 homodimers inhibit transcription of NF- $\kappa \mathrm{B}$ gene targets. However, p50 homodimers are reported to activate the production of IL-10 in macrophages. ${ }^{46,63}$ Furthermore, IL-10 stimulation of macrophages does not affect the ability of the alternative $N F-\kappa B$ pathway in these cells to respond to TNF- $\alpha$ and other TNF protein family members, many of which are present in the tumor microenvironment. ${ }^{61}$

These studies indicate that IL-10 creates a powerful feedback loop in TAMs. IL-10 stimulation reduces classical $\mathrm{NF}-\kappa \mathrm{B}$ responsiveness to TNF- $\alpha$ but does not completely eliminate the effect. This is predicted to result in much lower levels of inflammatory cytokine production in response to the constant presence of inflammatory cytokines in the tumor microenvironment, producing protumor smoldering inflammation. In addition, the alternative pathway is free to respond to a smaller subset of these cytokines, activating the tumorsupportive effect of this pathway. Finally, IL-10 stimulation activates a positive feedback loop of IL-10 production, effectively locking the macrophages in the TAM phenotype, unless something can disrupt this signaling loop. Transfection with I $\kappa \mathrm{B} \alpha$ siRNA not only decreases IL-10 mRNA but also increases the ability of transfected macrophages to respond to TNF- $\alpha$, indicating that it might be an effective therapeutic agent for disrupting the IL-10-positive feedback loop and abrogating the TAM phenotype.

Finally, the results suggest that crosstalk between the two pathways could also be leveraged to reduce the negative effects of the TAM phenotype. The expression of p52 increases following TNF- $\alpha$ stimulation, but this effect is inhibited by transfection with $\mathrm{I} \kappa \mathrm{B} \alpha$ siRNA (Figure $8 \mathrm{E}$ ). This effect may be the result of direct or indirect crosstalk and could indicate the potential possibility of knocking down of $\mathrm{I} \kappa \mathrm{B} \alpha$ having combinatorial effects by decreasing the potentially protumor effects of the alternative NF- $\kappa B$ pathway at the same time as activating the classical pathway.

\section{Conclusion}

Modulation of the functions of TAMs represents a therapeutic strategy with great potential, and NF- $\kappa \mathrm{B}$ signaling is known to be important for defining macrophage functions, thus suggesting that modulation of NF- $\kappa \mathrm{B}$ signaling within TAMs could represent a novel therapeutic strategy. In order to develop this new treatment, two components would be required: the methodology for manipulation of gene expression specifically within TAMs and a knowledge of the appropriate gene targets. The optimal strategy for manipulation of NF- $\kappa \mathrm{B}$ in TAMs to generate antitumor outcomes is currently unknown. To develop the methodology for manipulation of gene expression within TAMs, we have developed a targeted polymer nanoparticle that encapsulates and protects siRNA sequences to facilitate delivery of NF- $\kappa B$-specific siRNA to TAMs. The nanoparticles have a mannosylated surface designed to target the mannose receptor, which is upregulated in TAMs macrophages. In the studies reported here, we have shown that MnNPs could deliver efficacious amounts of functional siRNA for manipulating the NF- $\kappa B$ pathways in macrophages and were more specific than commercial transfection agents. MnNPs are taken up to a greater degree in macrophages with increased mannose receptor presence (induced by IL-4 stimulation) compared to wild-type macrophages. The enhanced uptake of MnNPs by IL-4-stimulated macrophages complements our previous results indicating that MnNP uptake is mannose dependent. Furthermore, uptake of untargeted particles by IL-4-stimulated macrophages was not different from uptake 
of the same particles by wild-type macrophages. There is greater overall uptake of the MnNPs than the OHNPs, and uptake of MnNPs occurs at earlier time points. A comparison of MnNPs and Lipofectamine revealed that MnNPs strongly transfect a small population of macrophages in the BMDM population while Lipofectamine moderately transfects a larger population of BMDMs. Together, these results indicate that we have developed a methodology that is capable of delivering siRNA with specificity for mannose receptor expressing TAMs.

We have performed studies to determine the appropriate $\mathrm{NF}-\mathrm{\kappa B}$ gene targets to induce antitumor characteristics in macrophages. Following delivery of I $\mathrm{I} B \alpha$ siRNA to macrophages by MnNPs, mRNA for I $\mathrm{I} B \alpha$ was decreased, and mRNA for a T-cell recruitment cytokine CXCL9 was increased. Furthermore, mRNA for the mannose receptor and for IL-10 were decreased, indicating a loss of immunosuppressive function and a potential mechanism for disrupting the positive feedback loop between TAMs and tumor cells, which is implicated in sustaining the TAM phenotype. Thus, our results suggest that utilizing MnNP-delivered I $\mathrm{B} \alpha$ siRNA to knockdown the inhibitor of the classical pathway and activating classical NF- $\mathrm{KB}$ activity represents an effective strategy. Although the NF- $\mathrm{KB}$ pathways have been implicated in the generation of many protumor characteristics in TAMs, strong and acute activation of the classical pathway appears to override the TAM phenotype and activate a classically immunogenic phenotype in these macrophages. There have been reports of siRNA activating transcriptional pathways in cells, but this has always been seen as an undesirable, off-target effect of transfection in general. Deliberate activation of a specific transcriptional pathway by using siRNA to knockdown an inhibitor of the pathway has not been reported and is a novel mechanism for manipulating cell phenotype.

The current studies demonstrate the development of a methodology for delivery of siRNA to TAMs together with the identification of an NF- $\mathrm{KB}$ pathway gene target that in combination can induce cytotoxic and immunostimulatory functions in TAMs. In future studies, we plan to test the efficacy of this strategy to modulate NF-kB in TAMs in vivo, and activate tumor immunity in solid tumors.

\section{Acknowledgments}

The work performed in this study was funded in part by a Collaborative Idea Award through the Department of Defense CDMRP Breast Cancer Research Program (W81XWH-111-0242 and W81XWH-11-1-0344) and by donations from
Mr Chris Hill via the Anglo-American Charity. Nanoparticle characterization was performed at the Vanderbilt Institute of Nanoscale Science and Engineering, using facilities renovated under National Science Foundation Grant ARI-R2 DMR-0963361. The authors would like to acknowledge Hongmei Li and Shann Yu for their work in the design and synthesis of mannosylated endosomal escape polymers. They would also like to thank Halina Onishko for instruction and advice regarding bone marrow-derived macrophage generation and handling.

\section{Disclosure}

The authors report no conflicts of interest in this work.

\section{References}

1. Cheever MA. Twelve immunotherapy drugs that could cure cancers. Immunol Rev. 2008;222:357-368.

2. Kalos M, June CH. Adoptive T cell transfer for cancer immunotherapy in the era of synthetic biology. Immunity. 2013;39:49-60.

3. Oeckinghaus A, Hayden MS, Ghosh S. Crosstalk in NF- $\kappa$ B signaling pathways. Nat Immunol. 2011;12:695-708.

4. Qian BZ, Pollard JW. Macrophage diversity enhances tumor progression and metastasis. Cell. 2010;141:39-51.

5. DeNardo DG, Brennan DJ, Rexhepaj E, et al. Leukocyte complexity predicts breast cancer survival and functionally regulates response to chemotherapy. Cancer Discov. 2011;1:54-67.

6. Mantovani A, Sozzani S, Locati M, Allavena P, Sica A. Macrophage polarization: tumor-associated macrophages as a paradigm for polarized M2 mononuclear phagocytes. Trends Immunol. 2002;23:549-555.

7. Ojalvo LS, King W, Cox D, Pollard JW. High-density gene expression analysis of tumor-associated macrophages from mouse mammary tumors. Am J Pathol. 2009;174:1048-1064.

8. Greten FR, Eckmann L, Greten TF, et al. Ikkbeta links inflammation and tumorigenesis in a mouse model of colitis-associated cancer. Cell. 2004;118:285-296.

9. Coussens LM, Werb Z. Inflammation and cancer. Nature. 2002;420: 860-867.

10. Van Ginderachter JA, Movahedi K, Hassanzadeh Ghassabeh G, et al. Classical and alternative activation of mononuclear phagocytes: picking the best of both worlds for tumor promotion. Immunobiology. 2006;211:487-501.

11. Baj-Krzyworzeka M, Baran J, Szatanek R, Stankiewicz D, Siedlar M, Zembala M. Prevention and reversal of tumor cell-induced monocyte deactivation by cytokines, purified protein derivative (Ppd), and antiIL-10 antibody. Cancer Immun. 2004;4:8.

12. Sica A, Saccani A, Bottazzi B, et al. Autocrine production of IL-10 mediates defective IL-12 production and NF-kappa B activation in tumor-associated macrophages. J Immunol. 2000;164:762-767.

13. DeNardo DG, Barreto JB, Andreu P, et al. Cd4(+) T cells regulate pulmonary metastasis of mammary carcinomas by enhancing protumor properties of macrophages. Cancer Cell. 2009;16:91-102.

14. Lin EY, Jones JG, Li P, et al. Progression to malignancy in the polyoma middle $\mathrm{T}$ oncoprotein mouse breast cancer model provides a reliable model for human diseases. Am J Pathol. 2003;163:2113-2126.

15. Lin EY, Pollard JW. Tumor-associated macrophages press the angiogenic switch in breast cancer. Cancer Res. 2007;67:5064-5066.

16. Qian B, Deng Y, Im JH, et al. A distinct macrophage population mediates metastatic breast cancer cell extravasation, establishment and growth. PLoS One. 2009; 4:e6562.

17. Lin EY, Nguyen AV, Russell RG, Pollard JW. Colony-stimulating factor 1 promotes progression of mammary tumors to malignancy. $J$ Exp Med. 2001;193:727-740. 
18. Stathopoulos GT, Sherrill TP, Han W, et al. Host nuclear factorkappaB activation potentiates lung cancer metastasis. Mol Cancer Res. 2008:6:364-371.

19. Zaynagetdinov R, Sherrill TP, Polosukhin VV, et al. A critical role for macrophages in promotion of urethane-induced lung carcinogenesis. J Immunol. 2011;187:5703-5711.

20. Sun SC. The noncanonical NF-кB pathway. Immunol Rev. 2012; 246:125-140.

21. Nathan C, Brukner L, Kaplan G, Unkeless J, Cohn Z. Role of activated macrophages in antibody-dependent lysis of tumor cells. J Exp Med. 1980;152:183-197.

22. Nathan C, Cohn Z. Role of oxygen-dependent mechanisms in antibodyinduced lysis of tumor cells by activated macrophages. J Exp Med. 1980;152:198-208.

23. Connelly L, Barham W, Onishko HM, et al. NF-kappaB activation within macrophages leads to an anti-tumor phenotype in a mammary tumor lung metastasis model. Breast Cancer Res. 2011;13:R83.

24. Connelly L, Jacobs AT, Palacios-Callender M, Moncada S, Hobbs AJ. Macrophage endothelial nitric-oxide synthase autoregulates cellular activation and pro-inflammatory protein expression. $J$ Biol Chem. 2003;278:26480-26487.

25. Bellas RE, FitzGerald MJ, Fausto N, Sonenshein GE. Inhibition of NF-kappa B activity induces apoptosis in murine hepatocytes. Am J Pathol. 1997;151:891-896.

26. Ben-Neriah Y, Karin M. Inflammation meets cancer, with NF- $\kappa B$ as the matchmaker. Nat Immunol. 2011;12:715-723.

27. Makarov SS. NF-kappaB as a therapeutic target in chronic inflammation: recent advances. Mol Med Today. 2000;6:441-448.

28. Bonizzi G, Karin M. The two NF-kappaB activation pathways and their role in innate and adaptive immunity. Trends Immunol. 2004;25: $280-288$.

29. Fire A, Xu S, Montgomery MK, Kostas SA, Driver SE, Mello CC. Potent and specific genetic interference by double-stranded RNA in Caenorhabditis elegans. Nature. 1998;391:806-811.

30. Behr JP. The proton sponge: a trick to enter cells that viruses did not exploit. Chimia. 1997;51:34-36.

31. Convertine AJ, Diab C, Prieve M, et al. pH-responsive polymeric micelle carriers for siRNA drugs. Biomacromolecules. 2010;11:2904-2911.

32. Evans BC, Nelson CE, Yu SS, et al. Ex vivo red blood cell hemolysis assay for the evaluation of $\mathrm{pH}$-responsive endosomolytic agents for cytosolic delivery of biomacromolecular drugs. J Vis Exp. 2013;73: e50166.

33. Boyer C, Bulmus V, Davis TP, Ladmiral V, Liu J, Perrier S. Bioapplications of raft polymerization. Chem Rev. 2009;109:5402-5436.

34. Allavena P, Chieppa M, Bianchi G, et al. Engagement of the mannose receptor by tumoral mucins activates an immune suppressive phenotype in human tumor-associated macrophages. Clin Dev Immunol. 2010; 2010:547179

35. Luo Y, Zhou H, Krueger J, et al. Targeting tumor-associated macrophages as a novel strategy against breast cancer. J Clin Invest. 2006;116: 2132-2141

36. Stahl PD, Ezekowitz RA. The mannose receptor is a pattern recognition receptor involved in host defense. Curr Opin Immunol. 1998;10: $50-55$.

37. Yu SS, Lau CM, Barham WJ, et al. Macrophage-specific RNA interference targeting via "click", mannosylated polymeric micelles. Mol Pharm. 2013;10:975-987.

38. Ortega RA, Barham WJ, Kumar B, et al. Biocompatible mannosylated endosomal-escape nanoparticles enhance selective delivery of short nucleotide sequences to tumor associated macrophages. Nanoscale. 2015;7:500-510.

39. Hagemann T, Lawrence T, McNeish I, et al. "Re-educating" tumorassociated macrophages by targeting NF-kappaB. J Exp Med. 2008;205: 1261-1268.

40. Yang J, Hawkins OE, Barham W, et al. Myeloid IKK $\beta$ promotes antitumor immunity by modulating CCL11 and the innate immune response. Cancer Res. 2014;74:7274-7284.
41. Everhart MB, Han W, Sherrill TP, et al. Duration and intensity of NF-kappaB activity determine the severity of endotoxin-induced acute lung injury. J Immunol. 2006;176:4995-5005.

42. Porcheray F, Viaud S, Rimaniol AC, et al. Macrophage activation switching: an asset for the resolution of inflammation. Clin Exp Immunol. 2005;142:481-489.

43. Han W, Joo M, Everhart MB, Christman JW, Yull FE, Blackwell TS. Myeloid cells control termination of lung inflammation through the NF-kappaB pathway. Am J Physiol Lung Cell Mol Physiol. 2009;296: L320-L327.

44. Roby KF, Taylor CC, Sweetwood JP, et al. Development of a syngeneic mouse model for events related to ovarian cancer. Carcinogenesis. 2000;21:585-591.

45. Mantovani A, Sica A. Macrophages, innate immunity and cancer: balance, tolerance, and diversity. Curr Opin Immunol. 2010;22:231-237.

46. Cao S, Zhang X, Edwards JP, Mosser DM. NF-kappaB1 (p50) homodimers differentially regulate pro- and anti-inflammatory cytokines in macrophages. J Biol Chem. 2006;281:26041-26050.

47. Levkau B, Scatena M, Giachelli CM, Ross R, Raines EW. Apoptosis overrides survival signals through a caspase-mediated dominantnegative NF-kappa B loop. Nat Cell Biol. 1999;1:227-233.

48. Wang Y, Mo X, Piper MG, et al. M-CSF induces monocyte survival by activating NF- $\mathrm{\kappa B}$ p 65 phosphorylation at Ser2 26 via protein kinase $\mathrm{C}$. PLoS One. 2011;6:e28081.

49. Fuseler JW, Merrill DM, Rogers JA, Grisham MB, Wolf RE. Analysis and quantitation of NF-kappa B nuclear translocation in tumor necrosis factor alpha (TNF-alpha) activated vascular endothelial cells. Microsc Microanal. 2006;12:269-276.

50. Roos C, Wicovsky A, Muller N, et al. Soluble and transmembrane TNF-like weak inducer of apoptosis differentially activate the classical and noncanonical NF-kappa B pathway. J Immunol. 2010;185: 1593-1605.

51. Chattopadhyay U, Bhattacharyya S, Chakrabarty NG. Tumor associated macrophage mediated lysis of autologous tumor cells. Neoplasma. 1986;33:157-165.

52. Cox GW. Assay for macrophage-mediated anti-tumor cytotoxicity. Curr Protoc Immunol. 2001; Chapter 14:Unit147.

53. Fiani ML, Beitz J, Turvy D, Blum JS, Stahl PD. Regulation of mannose receptor synthesis and turnover in mouse $\mathrm{J} 774$ macrophages. $J$ Leukoc Biol. 1998;64:85-91.

54. Ezekowitz RA, Sastry K, Bailly P, Warner A. Molecular characterization of the human macrophage mannose receptor: demonstration of multiple carbohydrate recognition-like domains and phagocytosis of yeasts in Cos-1 cells. J Exp Med. 1990;172:1785-1794.

55. Müller M, Carter S, Hofer MJ, Campbell IL. Review: the chemokine receptor CXCR3 and its ligands CXCL9, CXCL10 and CXCL11 in neuroimmunity - a tale of conflict and conundrum. Neuropathol Appl Neurobiol. 2010;36:368-387.

56. Palmer K, Hitt M, Emtage PC, Gyorffy S, Gauldie J. Combined CXC chemokine and interleukin-12 gene transfer enhances antitumor immunity. Gene Ther. 2001;8:282-290

57. Tannenbaum CS, Tubbs R, Armstrong D, Finke JH, Bukowski RM, Hamilton TA. The CXC chemokines IP-10 and Mig are necessary for IL-12-mediated regression of the mouse renca tumor. J Immunol. 1998;161:927-932.

58. Dudley ME, Rosenberg SA. Adoptive-cell-transfer therapy for the treatment of patients with cancer. Nat Rev Cancer. 2003;3:666-675.

59. Mantovani A, Sica A, Sozzani S, Allavena P, Vecchi A, Locati M. The chemokine system in diverse forms of macrophage activation and polarization. Trends Immunol. 2004;25:677-686.

60. Armstrong L, Jordan N, Millar A. Interleukin 10 (IL-10) regulation of tumour necrosis factor alpha (TNF-alpha) from human alveolar macrophages and peripheral blood monocytes. Thorax. 1996;51:143-149.

61. Driessler F, Venstrom K, Sabat R, Asadullah K, Schottelius AJ. Molecular mechanisms of interleukin-10-mediated inhibition of NFkappaB activity: a role for P50. Clin Exp Immunol. 2004;135:64-73. 
62. Smale ST. Hierarchies of NF- $\mathrm{KB}$ btarget-gene regulation. Nat Immunol. 2011;12:689-694.
63. Saraiva M, O'Garra A. The regulation of IL-10 production by immune cells. Nat Rev Immunol. 2010;10:170-181.

International Journal of Nanomedicine

\section{Publish your work in this journal}

The International Journal of Nanomedicine is an international, peerreviewed journal focusing on the application of nanotechnology in diagnostics, therapeutics, and drug delivery systems throughou the biomedical field. This journal is indexed on PubMed Central, MedLine, CAS, SciSearch ${ }^{\circledR}$, Current Contents ${ } /$ Clinical Medicine,
Journal Citation Reports/Science Edition, EMBase, Scopus and the Elsevier Bibliographic databases. The manuscript management system is completely online and includes a very quick and fair peer-review system, which is all easy to use. Visit http://www.dovepress.com/ testimonials.php to read real quotes from published authors.

Submit your manuscript here: http://www.dovepress.com/international-journal-of-nanomedicine-journal 